\title{
Randomized Comparison Study of Novel Recombinant Human Antithrombin Gamma and Plasma-Derived Antithrombin in Healthy Volunteers
}

\author{
Hidetoshi Furuie ${ }^{1} \cdot$ Hironori Kanda ${ }^{2}$
}

Published online: 6 September 2019

(c) The Author(s) 2019

\begin{abstract}
Background and Objective This paper describes two studies, which aimed to compare the safety and plasma antithrombin activity of recombinant human antithrombin gamma (rhAT-gamma) with plasma-derived antithrombin (pAT) 60 IU/kg, and to establish bioequivalence by adjusting the rhAT-gamma dose to that at which plasma antithrombin activity equaled that for pAT $60 \mathrm{IU} / \mathrm{kg}$, based on results of the first study.

Methods Healthy adult men aged 20-45 years received once-daily doses of rhAT-gamma or pAT intravenously for 3 days (first study: $60 \mathrm{IU} / \mathrm{kg}$ of each; second study: $72 \mathrm{IU} / \mathrm{kg}$ of rhAT-gamma and $60 \mathrm{IU} / \mathrm{kg}$ of pAT). Maximum plasma antithrombin activity after three doses $\left(C_{\text {max,day } 3}\right)$ and area under the plasma antithrombin activity-time curve after the third dose (AUC ${ }_{48-t}$ ) were analyzed. Safety was also assessed.

Results In the first study, we compared AUCs to $121 \mathrm{~h}$ (when the lower limit of quantification was first observed). Mean $C_{\text {max,day } 3}$ was $1.67 \mathrm{IU} / \mathrm{mL}$ in the rhAT-gamma group and $1.77 \mathrm{IU} / \mathrm{mL}$ in the pAT group; mean $\mathrm{AUC}_{48-121}$ was 58.44 and 71.94 $\mathrm{IU} \cdot \mathrm{h} / \mathrm{mL}$, respectively. Thus, we set the dose of rhAT-gamma in the second study to $72 \mathrm{IU} / \mathrm{kg}$. As a result, ratios of $C_{\max , \text { day } 3}$ and $\mathrm{AUC}_{48-t}$ in the rhAT-gamma vs. the pAT group were $105.7 \%$ (90\% confidence interval 100.3, 111.3) and 100.5\% (90\% confidence interval 91.5, 110.4), respectively. Adverse events were more frequent in the rhAT-gamma group.

Conclusions As $90 \%$ confidence intervals for $C_{\text {max,day } 3}$ and $\mathrm{AUC}_{48-t}$ ratios for rhAT-gamma:pAT were within the acceptability range for bioequivalence, rhAT-gamma (72 IU/kg) and pAT (60 IU/kg) are considered bioequivalent.
\end{abstract}

\section{Introduction}

The coagulation and fibrinolytic systems work in a careful balance to keep blood flowing smoothly without thrombus formation or bleeding. The coagulation system is activated in response to a break in a blood vessel. A cascade of reactions coagulates the blood to stem the flow through the break, and the fibrinolytic system quickly dissolves clots to re-establish smooth blood flow again. The two systems are

Electronic supplementary material The online version of this article (https://doi.org/10.1007/s40261-019-00847-9) contains supplementary material, which is available to authorized users.

Hidetoshi Furuie

hidetoshi.furuie@heishinkai.com

1 Osaka Pharmacology Clinical Research Hospital, 4-1-29

Miyahara, Yodogawa-ku, Osaka 532-0003, Japan

2 Kyowa Kirin Co, Ltd, Otemachi Financial City Grand Cube, 1-9-2 Otemachi, Chiyoda-ku, Tokyo 100-0004, Japan carefully coordinated: if either system malfunctions, this can result in thrombosis or excessive bleeding.

Antithrombin (AT) is a major coagulation inhibitor mainly synthesized in the liver [1]. This 58-kDa glycoprotein is a serine protease inhibitor that binds and inactivates thrombin and other coagulation factors, including factors IX, X, XI, and XII [2-4]. Antithrombin activity is enhanced 1000 -fold by heparin [5]. Antithrombin is located primarily in the blood and extravascular areas, including epithelial cells [6]. The AT concentration in blood from healthy adults is approximately $15-27 \mathrm{mg} / \mathrm{dL}$, and the AT half-life is approximately $65 \mathrm{~h} \mathrm{[7].}$

Antithrombin deficiency can be inherited or acquired [8, 9]. Congenital AT deficiency, which affects 1 in 2000 to 1 in 5000 people, typically presents with recurrent thrombosis from a young age [9]. Inherited AT deficiency is often caused by point mutations, deletions, or insertions in the AT gene SERPINC1 [10]. Acquired AT deficiency can result from reduced production or increased degradation of $\mathrm{AT}$ and is often associated with liver cirrhosis, nephrotic 


\section{Key Points}

In healthy adult men aged $20-45$ years, once-daily intravenous doses of recombinant human antithrombin gamma (rhAT-gamma) (72 IU/kg) or plasma-derived antithrombin (60 IU/kg) over 3 days demonstrated bioequivalence.

Treatment with once-daily rhAT-gamma for 3 days did not pose any safety concerns.

As a result, intravenous rhAT-gamma $600 \mathrm{IU}$ and 1800 IU formulations have been approved in Japan for the treatment of thrombophilia caused by congenital antithrombin deficiency and disseminated intravascular coagulation.

syndrome, disseminated intravascular coagulation, or thrombotic diseases.

Plasma-derived AT (pAT) products have been approved for the treatment of thrombogenic tendency attributed to congenital AT deficiency or disseminated intravascular coagulation with decreased AT [11]. Although existing pAT products are manufactured with safety measures to prevent the transmission of infectious diseases, these products may still contain an unknown infectious agent. Therefore, a recombinant human AT product could provide the same clinical benefits as the plasma-derived products, but without the risk of infection derived from human blood [12]. Furthermore, a recombinant form can be stably synthesized without relying on a supply of human plasma.

Human recombinant antithrombin alfa (rhAT-alfa) [ATryn ${ }^{\circledR}$; rEVO Biologics, Framingham, MA, USA] is a transgenic AT preparation purified from the milk of goats genetically engineered to produce human AT [13]. In 2008, the European Union approved rhAT-alfa for the prevention of venous thromboembolism during surgery for patients with congenital AT deficiency. In 2009, the USA approved rhAT-alfa for the prevention of thromboembolic events in patients with congenital AT deficiency during perioperative and perinatal periods [14]. The sugar chain structure of rhAT-alfa differs significantly from native AT [13]. Furthermore, rhAT-alfa is quickly cleared from the blood and must be administered continuously by intravenous injection for $24 \mathrm{~h}$ [14].

A new recombinant form of AT gamma (rhAT-gamma) has been produced in Chinese hamster ovary cells to overcome the limitations associated with rhAT-alfa and pAT. This product is the first AT preparation with a similar sugar chain structure to native human AT [15]. Using POTELLIGENT ${ }^{\circledR}$ technology (BioWa, Inc., Princeton, NJ, USA) [16], we focused on changing the oligosaccharide structure of human AT produced recombinantly in mammalian cells from the original mature complex-type lacking a core fucose to the immature high-mannose type. Chinese hamster ovary cell lines deficient in $\alpha$-1, 6-fucosyltransferase, and $N$-acetylglucosaminyltransferase-1 [17] were employed to generate homogeneous recombinant human ATs fully lacking a core fucose with complex (rhAT-Com) and high-mannose-type (rhAT-Man) oligosaccharides, respectively. Therefore, this rhAT-gamma preparation has similar pharmacokinetics and biological activities to native AT.

We report two randomized, parallel-group, phase I studies in healthy adult men given the AT products for 3 days. The studies were designed to evaluate the safety and pharmacokinetics of rhAT-gamma 60-72 IU/kg, and to compare the bioavailability and establish bioequivalence between rhATgamma and a pAT product (60 IU/kg).

\section{Methods}

\subsection{Ethical Considerations}

Protocols were approved by the Institutional Review Board at Osaka Pharmacology Clinical Research Hospital (Osaka, Japan). All subjects provided voluntary written informed consent before any study-specific procedures. This study was conducted at Osaka Pharmacology Clinical Research Hospital, in accordance with the ethical principles of the Declaration of Helsinki.

\subsection{Subjects}

Healthy adult men aged $20-45$ years with body mass index of $18.5-25.0 \mathrm{~kg} / \mathrm{m}^{2}$ at screening were enrolled. Subjects were excluded if they had a disease that required treatment, an allergy to the investigational drugs, a history of thrombosis or abnormal bleeding, a history of gastrointestinal hemorrhage, drug or alcohol dependence, a positive test for infectious disease, or a history of drug use within 4 weeks of study start. Subjects were also excluded if they had been previously treated with rhAT-gamma or had received another investigational drug within 4 months of study start. In addition, subjects were not eligible if, in the previous 3 months, they had been hospitalized, undergone surgery, or donated more than $200 \mathrm{~mL}$ of blood.

\subsection{Study Design and Treatments}

The first study was conducted to evaluate the plasma AT activity of rhAT-gamma and pAT (60 IU/kg). Twenty subjects were randomized $(1: 1)$ according to a randomly assigned allocation list. Either $60 \mathrm{IU} / \mathrm{kg}$ of rhAT-gamma 
or $60 \mathrm{IU} / \mathrm{kg}$ of pAT (Neuart ${ }^{\circledR}$ I.V.; Japan Blood Products Organization, Tokyo, Japan) was administered by intravenous drip over $1 \mathrm{~h}$. The individual dose was calculated using subject bodyweight the day before administration. The volume of drug solution given to each subject was set at $200 \mathrm{~mL}$. Subjects received once-daily doses for 3 days.

The second study was designed to establish bioequivalence of plasma AT activity between rhAT-gamma and pAT; the rhAT-gamma dose was reset to $72 \mathrm{IU} / \mathrm{kg}$ because our analyses in the first study showed that rhAT-gamma (72 IU/ $\mathrm{kg})$ and pAT (60 IU/kg) had similar plasma AT activity. Forty-two subjects were randomized (1:1) according to a randomly assigned allocation list in the second study. Subjects in both studies were kept in the clinical unit for 10 days, and returned for follow-up examinations 3, 7, and 14 weeks after study treatment (unpublished data on file; Kyowa Kirin Co, Ltd, Tokyo, Japan).

Importantly, the elimination half-lives of rhAT-gamma and pAT are extremely long ( $\sim 60 \mathrm{~h}$ and $\sim 50 \mathrm{~h}$, respectively), such that it would have been very difficult to conduct a crossover study [18]. A randomized parallel-group design, with specific reference to bioequivalence test guidelines for generic drugs, was therefore employed.

The rationale for a 3-day treatment phase with rhATgamma was based on the results of a phase I, single-dose $(60 \mathrm{IU} / \mathrm{kg})$ study in healthy adult male individuals, in which the mean peak plasma AT concentration $\left(C_{\max } 1.08 \mathrm{IU} /\right.$ $\mathrm{mL}$ ) occurred $1.13 \mathrm{~h}$ after starting administration, and data were calculated for up to $49 \mathrm{~h}$ after starting administration. However, considering the transition of plasma AT activity, and the lower limit of quantification after single doses of rhAT-gamma 60 and $120 \mathrm{IU} / \mathrm{kg}$, the area under the plasma concentration-time curve (AUC) ratio of $\mathrm{AUC}_{0-\imath} / \mathrm{AUC}_{0-\infty}$ for plasma AT activity after a single dose of rhAT-gamma $60 \mathrm{IU} / \mathrm{kg}$ was estimated to be about $65 \%$. This was considered inadequate for accurate comparison of pharmacokinetics. Therefore, we simulated plasma AT activity after rhAT-gamma $60 \mathrm{IU} / \mathrm{kg}$ administered once a day for 3 days; the simulation was based on data for plasma AT activity obtained in an earlier phase I study (unpublished data on file; Kyowa Kirin Co, Ltd). The ratio of $\mathrm{AUC}_{48-l} / \mathrm{AUC}_{48-\infty}$ for plasma AT activity (with $t$ as time when the lower limit of quantification was evident after 3 doses) was estimated to be about $75 \%$, which is close to the recommended value of $80 \%$ in Japanese bioequivalence guidelines [19]; thus, rhAT-gamma $60 \mathrm{IU} / \mathrm{kg}$ administered once a day for 3 days was compared with single-dose administration. Clinically, the study pAT preparation is administered for $2-5$ days; thus, the administration period was set as 3 days, considering the burden on subjects.

The study was conducted according to CONSORT guidelines. However, as a preliminary trial, the study was not registered with a clinical trial registry.

\subsection{Pharmacokinetic and Bioequivalence Analyses}

Plasma AT activity, plasma AT antigen concentration, and anti-Xa activity were analyzed: plasma AT activity by a chromogenic synthetic method using a validated test kit (at a centralized laboratory: SRL Medisearch Inc., Tokyo, Japan), which provides a measure of precision; and plasma AT antigen and anti-Xa activity were assessed by general test methods at the centralized laboratory. In the first study, blood samples for these analyses were obtained on days 1 and 2, immediately before administration of the investigational drug, and at 1,4 , and $10 \mathrm{~h}$ after administration of the investigational drug. On day 3, blood samples were obtained immediately before administration of the investigational drug, and at 1, 4, 10, 25, 49, and $73 \mathrm{~h}$ after administration. In the second study, blood samples were obtained on days 1 and 2, immediately before administration of the investigational drug, and at 1,4 , and $10 \mathrm{~h}$ after administration. On day 3, blood samples were obtained immediately before administration of the investigational drug, and at 1, 4, 10, 25, $49,73,97,121,145$, and $169 \mathrm{~h}$ after administration. From day 4 to day 10, samples were obtained daily. Blood samples were also obtained at the first follow-up visit ( 3 weeks after initial administration of the investigational drug). In both studies, the primary endpoints were peak plasma concentration after the third dose $\left(C_{\text {max,day } 3}\right)$ and $\mathrm{AUC}_{48-t}$, calculated from plasma AT activity during the study period. Thus, AUC ${ }_{48-t}$ was the area under the plasma AT activity time curve from $48 \mathrm{~h}$ after the first dose until the last time point at which plasma AT activity could be detected using the linear trapezoidal method. The pharmacokinetic parameters measured after three doses were used so that the AUC could be sufficiently evaluated. Importantly, the dose of rhAT-gamma showing bioequivalence with pAT $(60 \mathrm{IU} / \mathrm{kg})$ in the first study was then examined in the second study based on firststudy ratios for $C_{\text {max,day } 3}$ and $\mathrm{AUC}_{48-t}$. As $t$ for rhAT-gamma activity was $121 \mathrm{~h}$, and that for pAT activity was $168 \mathrm{~h}$, AUC from 48 to $121 \mathrm{~h}$ after initial administration $\left(\mathrm{AUC}_{48-121}\right)$ was calculated using the linear trapezoidal method in all subjects.

Secondary endpoints included plasma AT activity; AT antigen concentration; anti-Xa activity; and additional pharmacokinetic parameters calculated from plasma AT activity, plasma antigen concentrations, and plasma anti-Xa. For these parameters, we used the value obtained by subtracting the pre-administration value from the value obtained after administration of the investigational drug, as the resulting value was considered to be derived from the effect of the administered investigational drug and endogenous AT.

\subsection{Safety}

The safety of rhAT-gamma was assessed in both studies. Hematology, blood biochemistry, urinalysis, 
coagulation-fibrinolysis test values, bodyweight, blood pressure, pulse rate, and body temperature were assessed at screening, the day before investigational drug administration, during the 3-day administration period, and at the first follow-up visit. Blood pressure, pulse rate, and body temperature were also assessed daily from day 4 onwards. Subjects were also assessed by 12-lead electrocardiography and funduscopy at screening, day 10, and the first followup visit. All adverse events (AEs) were coded with Lowest Level Terms of the Japanese version of the International Conference on Harmonization Medical Dictionary for Regulatory Activities Version 12.1 in the first study, and Version 13.1 in the second study.

\subsection{Statistical Methods}

Assuming that there was no difference between rhATgamma and pAT, the $90 \%$ confidence interval $(\mathrm{CI})$ for the difference in mean log-transformed $C_{\max }$ and $\mathrm{AUC}_{0-t}$ fell between $\log (0.80)$ and $\log (1.25)$, with a probability of $\geq 90 \%$ and a sample size of eight subjects per group. In the first study, $C_{\text {max,day } 3}$ and $\mathrm{AUC}_{48-t}$ were used as indices. Thus, considering a possible increase in variance, the sample size was set at ten subjects per group.

Sample size for the second study was based on mean and variance of the log-transformed $C_{\text {max,day } 3}$ and $\mathrm{AUC}_{48-t}$ of rhAT-gamma obtained from the first study and the estimated $C_{\text {max,day3 }}$ and $\mathrm{AUC}_{48-t}$ of rhAT-gamma administered at a 1.2fold dose of the pAT dose. It was estimated that a sample size of 42 subjects ( 21 subjects per group) would allow for a probability $\geq 80 \%$ and that the $90 \% \mathrm{CI}$ for the difference in mean $\log$-transformed $C_{\text {max,day } 3}$ and $\mathrm{AUC}_{48-t}$ would fall within the bioequivalence criteria (80-125\%) [19]. The regulatory criteria for bioequivalence states that blood sampling should be continued until $\mathrm{AUC}_{0-t}$ is over $80 \%$ of $\mathrm{AUC}_{0-\infty}$ (normally more than three times the elimination half-life after $t_{\max }$ ) [19].

In the first study, the primary endpoints were $C_{\max , \text { day } 3}$, and $\mathrm{AUC}_{48-t}$, which were calculated from plasma AT activity (with pre-dose adjustment) at the time of administration of rhAT-gamma or pAT. Secondary endpoints were $C_{\text {max,day } 1}$, $C_{\text {max,day } 2}, t_{\text {max,day } 3}, \mathrm{AUC}_{0-t}, \mathrm{AUC}_{0-\infty}$, elimination half-life $\left(t_{1 / 2}\right)$, mean residence time (MRT), and the elimination rate constant $\left(k_{\mathrm{el}}\right)$, which were calculated from plasma AT activity (with pre-dose adjustment) at the time of administration of rhAT-gamma or pAT. Values for $C_{\max , d a y 3 \text { (antithrombin) }}$ and $\mathrm{AUC}_{48-t \text { (antithrombin) }}$ were calculated from plasma AT-antigen concentrations (with pre-dose adjustment). Plasma AT activity, AT antigen concentration, and plasma anti-Xa activity (with pre-dose adjustment) were at the time of administration of rhAT-gamma or pAT.

In the second study, the primary endpoints were $C_{\text {max,day3 }}$ and $\mathrm{AUC}_{48-t}$, which were calculated from plasma AT activity at the time of administration of rhAT-gamma or pAT.
Secondary endpoints were incremental recovery, $C_{\text {max,day } 1}$, $C_{\text {max,day } 2}, t_{\text {max,day } 3}, \mathrm{AUC}_{0-t}, \mathrm{AUC}_{0-\infty}, t_{1 / 2}, \mathrm{MRT}$, and $k_{\mathrm{el}}$, which were calculated from plasma AT activity at the time of administration of rhAT-gamma or pAT. Values for $C_{\text {max,day3 (antithrombin) }}$ and $\mathrm{AUC}_{48-t \text { (antithrombin) }}$ were calculated from plasma AT antigen concentration. Values for $C_{\text {max,day3 (anti-Xa) }}$ and $\mathrm{AUC}_{48-t \text { (anti-Xa) }}$ were calculated from plasma anti-Xa activity. Plasma AT activity, AT antigen concentration, and anti-Xa activity were at the time of administration of rhAT-gamma or pAT.

Categorical data were summarized with frequency and percentage, and continuous data were summarized with descriptive statistics, including the number of subjects, mean, standard deviation (SD), minimum, median, and maximum. Pharmacokinetic parameters were analyzed by an analysis of variance (ANOVA) with treatment group as a factor. Parameters, except for time to $C_{\text {max,day } 3}\left(t_{\max , \text { day } 3}\right)$, were analyzed after $\log$ transformation. Based on the guidelines for bioequivalence studies of generic drugs, we used $90 \%$ CIs for the evaluation of bioequivalence. The null hypothesis was that mean values in the two groups were equivalent. In addition, a $90 \%$ CI for the between-group difference in the mean log-transformed value for each parameter was calculated. If the $90 \%$ CIs for differences in mean $\log$-transformed $C_{\text {max,day } 3}$ and $\mathrm{AUC}_{48-t}$ values were between $\log (0.80)$ and $\log (1.25)$, the two treatments were considered bioequivalent [19].

Adverse events were tabulated for each treatment group. SAS $^{\circledR}$ version 9.1.3 (SAS Inc.; Cary, NC, USA) was used for statistical analyses, and Phoenix ${ }^{\circledR}$ WinNonlin ${ }^{\circledR}$ versions 5.2.1 and 6.1 (Certara Inc., Princeton, NJ, USA) were used for calculation of pharmacokinetic parameters.

\section{Results}

\subsection{Subjects}

Subject baseline demographics are summarized in Table 1 . All baseline demographic and clinical characteristics were similar in both subject groups in each of the studies.

\subsection{Pharmacokinetics and Bioequivalence}

In the first study, plasma AT activity after the third dose (48 $\mathrm{h}$ after the first dose) remained lower in the rhAT-gamma than pAT group (Fig. 1; Table 2). Arithmetic mean $C_{\text {max,day3 }}$ of plasma AT activity, a primary endpoint, was 1.67 in the rhAT-gamma group and $1.77 \mathrm{IU} / \mathrm{mL}$ in the $\mathrm{pAT}$ group, with no statistically significant difference $(p=0.268)$. Arithmetic mean $\mathrm{AUC}_{48-t,}$, another primary endpoint, was $58.44 \mathrm{IU} \cdot \mathrm{h} /$ $\mathrm{mL}$ in the rhAT-gamma group and $91.44 \mathrm{IU} \cdot \mathrm{h} / \mathrm{mL}$ in the pAT group, a difference that was statistically significant $(p<0.001)$, supporting the increase in dose of rhAT-gamma 
Table 1 Baseline demographic and clinical characteristics of subjects

\begin{tabular}{|c|c|c|c|c|}
\hline \multirow[t]{2}{*}{ Characteristics } & \multicolumn{2}{|l|}{ First study } & \multicolumn{2}{|l|}{ Second study } \\
\hline & $\begin{array}{l}\text { rhAT-gamma } \\
60 \mathrm{IU} / \mathrm{kg} \\
(n=10)\end{array}$ & $\begin{array}{l}\mathrm{pAT} \\
60 \mathrm{IU} / \mathrm{kg} \\
(n=10)\end{array}$ & $\begin{array}{l}\text { rhAT-gamma } \\
72 \mathrm{IU} / \mathrm{kg} \\
(n=21)\end{array}$ & $\begin{array}{l}\mathrm{pAT} \\
60 \mathrm{IU} / \mathrm{kg} \\
(n=21)\end{array}$ \\
\hline Age, years $($ mean $\pm S D)$ & $21.6 \pm 1.3$ & $22.1 \pm 1.7$ & $24.6 \pm 4.7$ & $24.3 \pm 3.9$ \\
\hline Height, cm $($ mean $\pm \mathrm{SD})$ & $170.9 \pm 4.8$ & $173.5 \pm 5.6$ & $168.0 \pm 3.7$ & $168.7 \pm 5.1$ \\
\hline Bodyweight, $\mathrm{kg}($ mean $\pm \mathrm{SD})$ & $59.1 \pm 6.9$ & $64.3 \pm 4.5$ & $55.6 \pm 2.3$ & $55.4 \pm 2.5$ \\
\hline BMI, $\mathrm{kg} / \mathrm{m}^{2}($ mean $\pm \mathrm{SD})$ & $20.2 \pm 1.7$ & $21.4 \pm 1.6$ & $19.7 \pm 0.7$ & $19.5 \pm 0.7$ \\
\hline Past history, comorbidities, $n(\%)$ & $2(20)$ & $1(10)$ & $7(33.3)$ & $9(42.9)$ \\
\hline
\end{tabular}

Values shown are arithmetic means

$B M I$ body mass index, $p A T$ plasma antithrombin, rhAT-gamma recombinant human antithrombin-gamma, $S D$ standard deviation

Fig. 1 Time course of plasma antithrombin (AT) activity [linear plot; mean \pm standard deviation (SD)] in subjects treated with three daily doses of $60 \mathrm{IU} / \mathrm{kg}$ of recombinant human antithrombin gamma (rhATgamma) $(n=10)$ or $60 \mathrm{IU} / \mathrm{kg}$ of plasma-derived antithrombin $(\mathrm{pAT})(n=10)$

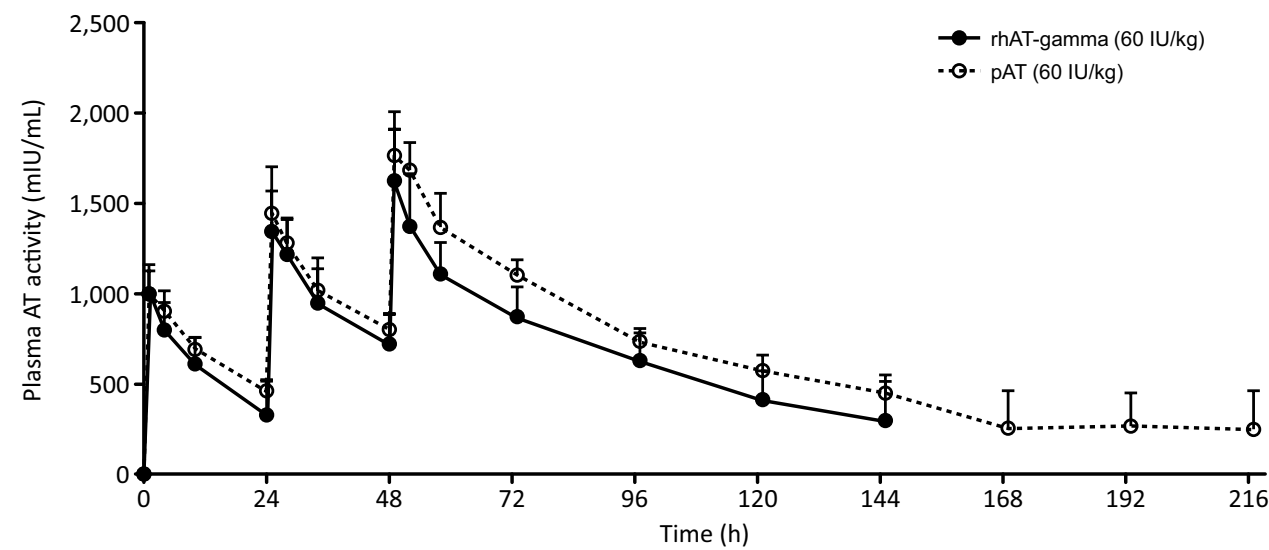

Table 2 Primary endpoints $\left(C_{\max , \text { day } 3}, \mathrm{AUC}_{48-t}\right)$ in all treatment groups

\begin{tabular}{|c|c|c|c|c|c|c|c|c|}
\hline & $\begin{array}{l}\text { Pharmacokinetic } \\
\text { parameter }\end{array}$ & Treatment group & $n$ & Mean \pm SD & $\begin{array}{l}\text { Geometric } \\
\text { mean }\end{array}$ & $\begin{array}{l}\text { Difference }^{a} \\
\text { Estimate }(90 \% \text { CI) }\end{array}$ & $\begin{array}{l}\text { Ratio }^{\mathrm{b}} \\
\text { Estimate }(90 \% \text { CI })\end{array}$ & $P$ value ${ }^{\mathrm{c}}$ \\
\hline \multirow{6}{*}{$\begin{array}{l}\text { First } \\
\text { study }\end{array}$} & \multirow[t]{2}{*}{$C_{\text {max,day } 3}(\mathrm{IU} / \mathrm{mL})$} & rhAT-gamma & 10 & $1.67 \pm 0.31$ & 1.64 & \multirow{2}{*}{$\begin{array}{l}-0.0332 \\
(-0.0835,0.0172)\end{array}$} & \multirow{2}{*}{$\begin{array}{l}92.7 \\
(82.5,104.0)\end{array}$} & \multirow[t]{2}{*}{0.268} \\
\hline & & pAT & 10 & $1.77 \pm 0.16$ & 1.77 & & & \\
\hline & \multirow[t]{2}{*}{$\mathrm{AUC}_{48-t}(\mathrm{IU} \cdot \mathrm{h} / \mathrm{mL})^{\mathrm{d}}$} & rhAT-gamma & 10 & $58.44 \pm 11.72$ & 57.46 & \multirow{2}{*}{$\begin{array}{l}-0.1995 \\
(-0.2520,-0.1471)\end{array}$} & \multirow{2}{*}{$\begin{array}{l}63.2 \\
(56.0,71.3)\end{array}$} & \multirow[t]{2}{*}{$<0.001$} \\
\hline & & pAT & 10 & $91.44 \pm 9.58$ & 90.97 & & & \\
\hline & \multirow[t]{2}{*}{$\mathrm{AUC}_{48-121}(\mathrm{IU} \cdot \mathrm{h} / \mathrm{mL})$} & rhAT-gamma & 10 & $58.44 \pm 11.72$ & 57.46 & \multirow{2}{*}{$\begin{array}{l}-0.0965 \\
(-0.1454,-0.476)\end{array}$} & \multirow{2}{*}{$\begin{array}{l}80.1 \\
(71.5,89.6)\end{array}$} & \multirow[t]{2}{*}{0.003} \\
\hline & & pAT & 10 & $71.94 \pm 5.29$ & 71.76 & & & \\
\hline \multirow{4}{*}{$\begin{array}{r}\text { Second } \\
\text { study }\end{array}$} & \multirow[t]{2}{*}{$C_{\text {max,day3 }}(\mathrm{IU} / \mathrm{mL})$} & rhAT-gamma & 21 & $2.08 \pm 0.17$ & 2.08 & \multirow{2}{*}{$\begin{array}{l}0.0239 \\
(0.0014,0.0463)\end{array}$} & \multirow{2}{*}{$\begin{array}{l}105.7 \\
(100.3,111.3)\end{array}$} & \multirow[t]{2}{*}{0.081} \\
\hline & & pAT & 20 & $1.98 \pm 0.23$ & 1.97 & & & \\
\hline & \multirow[t]{2}{*}{$\mathrm{AUC}_{48-t}(\mathrm{IU} \cdot \mathrm{h} / \mathrm{mL})^{\mathrm{d}}$} & rhAT-gamma & 21 & $98.71 \pm 13.94$ & 97.65 & \multirow{2}{*}{$\begin{array}{l}0.0023 \\
(-0.0385,0.0430)\end{array}$} & \multirow{2}{*}{$\begin{array}{l}100.5 \\
(91.5,110.4)\end{array}$} & \multirow[t]{2}{*}{0.926} \\
\hline & & pAT & 20 & $98.99 \pm 19.82$ & 97.15 & & & \\
\hline
\end{tabular}

$A T$ antithrombin, $A U C_{48-t}$ area under the curve up to the time $(\mathrm{t})$ when a decrease in the plasma AT activity below the lower limit of quantification was first observed after the third dose ( $48 \mathrm{~h}$ after the first dose), $C I$ confidence interval, $C_{\text {max }}$ day 3 maximum serum concentration after the third dose, $p A T$ plasma-derived antithrombin, rhAT-gamma recombinant human antithrombin gamma, $S D$ standard deviation

${ }^{a}$ rhAT-gamma - pAT

${ }^{\mathrm{b}}$ Calculated by inverse transformation of difference (geometric means)

${ }^{\mathrm{c}}$ Analysis of variance in a model with administration group as the fixed effect

${ }^{\mathrm{d}}$ AUC is not directly dose proportional for rhAT-gamma. When AT activity is less than the lower limit of quantification, it is described as zero, but it is not actually zero. Thus, $\mathrm{AUC}_{0-t}$ for rhAT-gamma in the first study is thought to be underestimated 
in the second study. Ratios of plasma AT activity $C_{\text {max,day3 }}$ and $\mathrm{AUC}_{48-t}$ in the rhAT-gamma vs. pAT groups, estimated from differences in log-transformed mean values between these groups were $92.6 \%$ (90\% CI 82.5, 104.0) and 63.2\% (90\% CI 56.0, 71.3), respectively.

We adopted $\mathrm{AUC}_{48-121}$, not $\mathrm{AUC}_{48-t}$, to determine the dose to be used in the second study, because $t$ was very different between rhAT-gamma and pAT, and the lower limit of quantification was first observed among subjects at $121 \mathrm{~h}$. Mean $\mathrm{AUC}_{48-121}$ was 58.44 in the rhAT-gamma group and $71.94 \mathrm{IU} \cdot \mathrm{h} / \mathrm{mL}$ in the pAT group. $\mathrm{AUC}_{48-121}$ for $\mathrm{pAT}$ was 1.2-fold higher than that for rhAT-gamma, and was expected to result in comparable $C_{\text {max,day } 3}$ and $\mathrm{AUC}_{48-t}$. Therefore, the dose of rhAT-gamma for the second study was set to $72 \mathrm{IU} / \mathrm{kg}$.

In the second study, the time course of plasma AT activity was similar for the two products (Fig. 2). Arithmetic mean $C_{\text {max,day3 }}$ of plasma AT activity was 2.08 in the rhATgamma group and $1.98 \mathrm{IU} / \mathrm{mL}$ in the pAT group $(p=0.081)$ (Table 2). Arithmetic mean $\mathrm{AUC}_{48-t}$ was 98.71 in the rhAT-gamma group and $98.99 \mathrm{IU} \cdot \mathrm{h} / \mathrm{mL}$ in the pAT group. Ratios of plasma AT activity $C_{\text {max,day } 3}$ and $\mathrm{AUC}_{48-t}$ in the rhAT-gamma vs. pAT group, calculated from differences in log-transformed mean values between these groups, were $105.7 \%$ (90\% CI 100.3, 111.3) and 100.5\% (90\% CI 91.5, 110.4), respectively. Thus, bioequivalence of rhAT-gamma at $72 \mathrm{IU} / \mathrm{kg}$ and pAT at $60 \mathrm{IU} / \mathrm{kg}$ was confirmed.

The incremental recovery (ratio of $C_{\max }$ to dose) was $1.69 \pm 0.17 \% / \mathrm{IU} / \mathrm{kg}($ mean $\pm \mathrm{SD})$ in the rhAT-gamma group and $1.84 \pm 0.20 \% / \mathrm{IU} / \mathrm{kg}$ in the pAT group (Table 3). For other parameters, in the rhAT-gamma and pAT groups, $C_{\text {max,day } 1}($ mean $\pm \mathrm{SD}$ ) was $1.21 \pm 0.12$ and $1.10 \pm 0.12 \mathrm{IU} /$ $\mathrm{mL}$, respectively, and the ratio of plasma AT activity $C_{\text {max,day } 1}$ in the rhAT-gamma vs. pAT group was $110.0 \%$ (90\% CI $104.2,116.1) ; t_{1 / 2}$ after the third dose was $81.82 \pm 50.07$ and $58.02 \pm 18.52 \mathrm{~h}$, respectively; MRT was $128.10 \pm 53.96$ and $102.40 \pm 21.00 \mathrm{~h}$, respectively; and $k_{\mathrm{el}}$ was $0.0101 \pm 0.0032$ and $0.0130 \pm 0.0038 \mathrm{~L} / \mathrm{h}$, respectively
(Table 3). An ANOVA with the treatment group as a factor revealed significant differences for $C_{\text {max,day } 1}, t_{1 / 2}$, MRT, and $k_{\mathrm{el}}(p<0.05)$ (Table 3).

In the first study, mean $\pm \mathrm{SD} C_{\text {max,day } 3}$ for plasma AT antigen was $48.4 \pm 6.7 \mathrm{mg} / \mathrm{dL}$ in the rhAT-gamma group and $47.5 \pm 5.4 \mathrm{mg} / \mathrm{dL}$ in the pAT group. Mean $\pm \mathrm{SD} \mathrm{AUC}_{48-t}$ for plasma AT antigen in these groups was $2216 \pm 199 \mathrm{mg} \cdot \mathrm{h} / \mathrm{dL}$ and $2662 \pm 149 \mathrm{mg} \cdot \mathrm{h} / \mathrm{dL}$, respectively (Fig. 3).

In the second study, mean $\pm \mathrm{SD} C_{\text {max,day } 3}$ for plasma $\mathrm{AT}$ antigen was $63.3 \pm 4.6 \mathrm{mg} / \mathrm{dL}$ in the rhAT-gamma group and $55.0 \pm 5.4 \mathrm{mg} / \mathrm{dL}$ in the pAT group, while mean $\pm \mathrm{SD}$ $\mathrm{AUC}_{48-t}$ for plasma AT antigen was $3234 \pm 341 \mathrm{mg} \cdot \mathrm{h} / \mathrm{dL}$ and $3161 \pm 438 \mathrm{mg} \cdot \mathrm{h} / \mathrm{dL}$, respectively (Fig. 4). Thus, in the first study, levels of plasma AT antigen were lower in the rhATgamma than pAT group, whereas in the second study there was no obvious difference between groups.

In the first study, mean $\pm \mathrm{SD} C_{\max , \text { day } 3}$ for anti-Xa activity was $178 \pm 14 \%$ in the rhAT-gamma group and $178 \pm 14 \%$ in the pAT group, while mean $\pm \mathrm{SD} \mathrm{AUC}_{48-121}$ for anti-Xa activity was $6736 \pm 770 \% \cdot h$ and $10,280 \pm 1060 \%$ h, respectively (Fig. 5). In the second study, mean $\pm \mathrm{SD} C_{\text {max,day } 3}$ for anti-Xa activity was $215 \pm 20 \%$ in the rhAT-gamma group and $203 \pm 20 \%$ in the pAT group, while mean \pm SD $\mathrm{AUC}_{48-t}$ for anti-Xa activity was $11,940 \pm 1000 \% \cdot \mathrm{h}$ and $11,600 \pm 1280 \% \cdot h$, respectively (Fig. 6). Thus, in the first study, anti-Xa activity was lower in the rhAT-gamma than pAT group, whereas in the second study there was no obvious difference in anti-Xa activity between groups.

\subsection{Safety}

In the first study, AEs occurred in two (20\%) of the ten subjects in the rhAT-gamma group [Electronic Supplementary Material (ESM)]. These events were alanine aminotransferase increased, aspartate aminotransferase (AST) increased, and eosinophil percentage increased in one subject (10\%); and erythema in the other subject (10\%). All AEs were mild. Adverse drug reactions (ADRs) occurred in one
Fig. 2 Time course of plasma antithrombin (AT) activity [linear plot; mean \pm standard deviation (SD)] in subjects treated with three daily doses of $72 \mathrm{IU} / \mathrm{kg}$ of recombinant human antithrombin gamma (rhATgamma) $(n=21)$ or $60 \mathrm{IU} / \mathrm{kg}$ of plasma-derived antithrombin (pAT) $(n=21)$

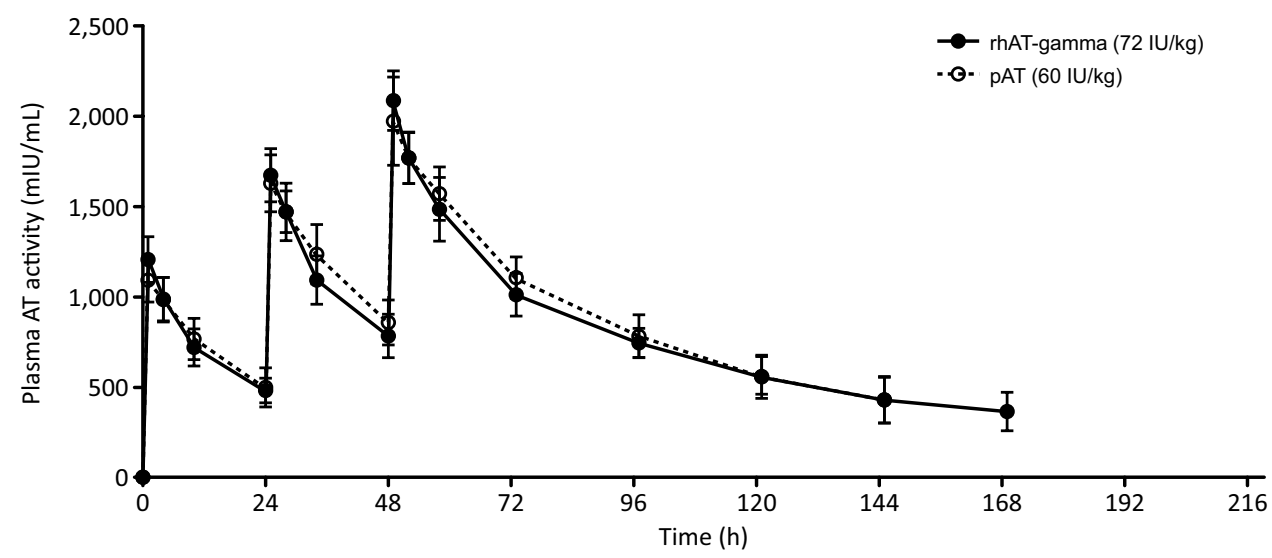


Table 3 Secondary endpoints (pharmacokinetic parameters after the third dose) in the second study

\begin{tabular}{|c|c|c|c|c|c|c|}
\hline Pharmacokinetic parameter & Treatment group & $n$ & Mean \pm SD & Geometric mean & $\begin{array}{l}\text { Ratio }^{\text {a }} \\
\text { Estimate }(90 \% \text { CI })\end{array}$ & $P$-value ${ }^{\mathrm{b}}$ \\
\hline \multirow[t]{2}{*}{ Incremental recovery $(\% / \mathrm{IU} / \mathrm{kg})$} & rhAT-gamma & 21 & $1.69 \pm 0.17$ & 1.68 & NA & NA \\
\hline & pAT & 21 & $1.84 \pm 0.20$ & 1.83 & & \\
\hline \multirow[t]{2}{*}{$t_{\text {max,day } 3}(\mathrm{~h})$} & rhAT-gamma & 21 & $1.00 \pm 0.00$ & 1.00 & NA & 0.068 \\
\hline & pAT & 20 & $1.45 \pm 1.10$ & 1.23 & & \\
\hline \multirow[t]{2}{*}{$C_{\text {max,day } 1}(\mathrm{IU} / \mathrm{mL})$} & rhAT-gamma & 21 & $1.21 \pm 0.12$ & 1.21 & $110.0(104.2,116.1)$ & $<0.001$ \\
\hline & pAT & 21 & $1.10 \pm 0.12$ & 1.10 & & \\
\hline \multirow[t]{2}{*}{$C_{\text {max,day } 2}(\mathrm{IU} / \mathrm{mL})$} & rhAT-gamma & 21 & $1.68 \pm 0.15$ & 1.67 & $103.0(97.8,108.5)$ & 0.338 \\
\hline & pAT & 20 & $1.63 \pm 0.16$ & 1.62 & & \\
\hline \multirow[t]{2}{*}{$\mathrm{AUC}_{0-t}(\mathrm{IU} \cdot \mathrm{h} / \mathrm{mL})$} & rhAT-gamma & 21 & $142.86 \pm 16.21$ & 141.88 & $98.9(91.7,106.6)$ & 0.801 \\
\hline & pAT & 20 & $145.25 \pm 23.37$ & 143.49 & & \\
\hline \multirow[t]{2}{*}{$\mathrm{AUC}_{0-\infty}(\mathrm{IU} \cdot \mathrm{h} / \mathrm{mL})$} & rhAT-gamma & 18 & $188.27 \pm 34.71$ & 185.68 & $106.8(96.7,117.9)$ & 0.270 \\
\hline & pAT & 18 & $176.75 \pm 33.63$ & 173.86 & & \\
\hline \multirow[t]{2}{*}{$t_{1 / 2}(\mathrm{~h})$} & rhAT-gamma & 18 & $81.82 \pm 50.07$ & 73.47 & $132.4(107.5,163.0)$ & $<0.05$ \\
\hline & $\mathrm{pAT}$ & 18 & $58.02 \pm 18.52$ & 55.50 & & \\
\hline \multirow[t]{2}{*}{ MRT (h) } & rhAT-gamma & 18 & $128.10 \pm 53.96$ & 121.33 & $120.7(104.4,139.6)$ & $<0.05$ \\
\hline & pAT & 18 & $102.40 \pm 21.00$ & 100.50 & & \\
\hline \multirow[t]{2}{*}{$k_{\mathrm{el}}(\mathrm{L} / \mathrm{h})$} & rhAT-gamma & 18 & $0.0101 \pm 0.0032$ & 0.0094 & $75.5(61.3,93.1)$ & $<0.05$ \\
\hline & pAT & 18 & $0.0130 \pm 0.0038$ & 0.0125 & & \\
\hline
\end{tabular}

$A U C_{0-t}$ area under the plasma concentration-time curve, $A U C_{0-\infty}$ area under the curve from time 0 extrapolated to infinite time, $C I$ confidence interval, $C_{\text {max,dayl }}$ maximum concentration after the first dose, $C_{\text {max,day } 2}$ maximum concentration after the second dose, $k_{e l}$ elimination rate constant, $M R T$ mean resonance time, $N A$ not available, $p A T$ plasma-derived AT, rhAT-gamma recombinant human antithrombin gamma, $S D$ standard deviation, $t_{1 / 2}$ half-life, $t_{\max \text {,day } 3}$ time to the maximum concentration after the third dose

${ }^{a}$ Calculated by inverse transformation of difference (geometric means)

${ }^{b}$ Analysis of variance in a model with administration group as the fixed effect

Fig. 3 Time course of plasma antithrombin (AT) antigen concentration [linear plot; mean \pm standard deviation (SD)] in subjects treated with three daily doses of $60 \mathrm{IU} / \mathrm{kg}$ of recombinant human antithrombin gamma (rhAT-gamma) $(n=10)$ or $60 \mathrm{IU} / \mathrm{kg}$ of plasmaderived antithrombin (pAT) $(n=10)$

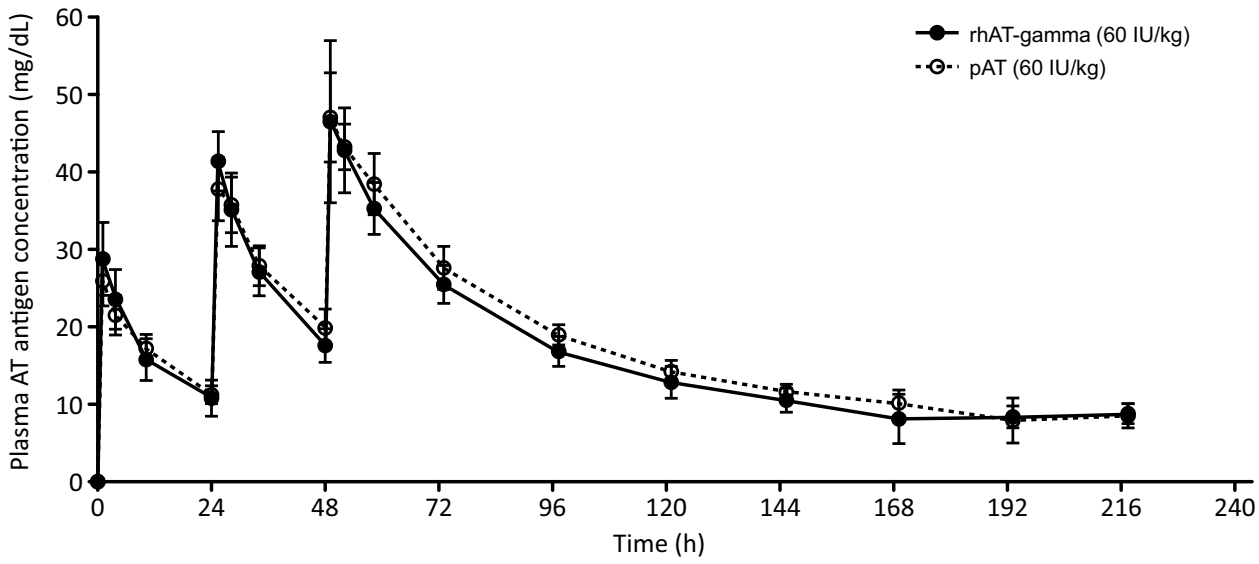

$(10 \%)$ of the ten subjects in the rhAT-gamma group. These ADRs were alanine aminotransferase increased and AST increased. Both events were mild in severity and resolved without intervention.

In the second study, AEs occurred in 13 (61.9\%) of the 21 subjects in the $72 \mathrm{IU} / \mathrm{kg}$ rhAT-gamma group, and in four (19.0\%) of the 21 subjects in the pAT group (ESM). Adverse events that occurred in more than one subject in the $72 \mathrm{IU} / \mathrm{kg}$
rhAT-gamma group were C-reactive protein (CRP) increased in three subjects $(14.3 \%)$, and pericoronitis, activated partial thromboplastin time prolonged, AST increased, and headache in two subjects $(9.5 \%)$ each. The CRP elevation was linked to pericoronitis in one case; however, no instance of CRP elevation was linked with elevated hepatic enzyme levels. No AEs were observed in more than one subject in the pAT group. Pericoronitis was rated as moderate in severity, 
Fig. 4 Time course of plasma antithrombin (AT) antigen concentration [linear plot; mean \pm standard deviation (SD)] in subjects treated with three daily doses of $72 \mathrm{IU} / \mathrm{kg}$ of recombinant human antithrombin gamma (rhAT-gamma) $(n=21)$ or $60 \mathrm{IU} / \mathrm{kg}$ of plasmaderived antithrombin (pAT) $(n=21)$

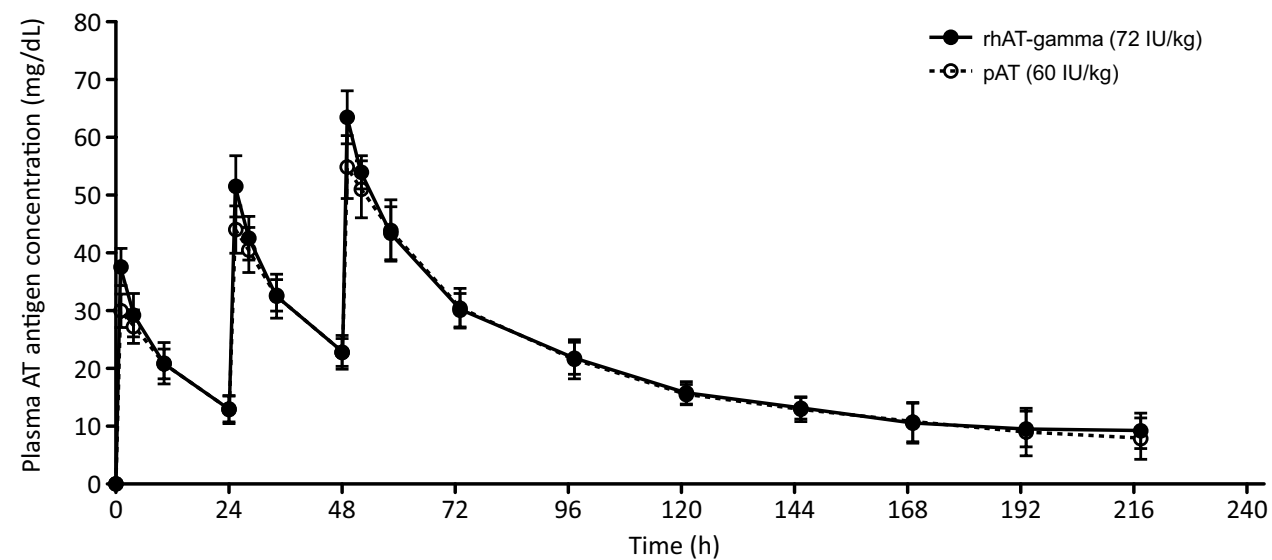

Fig. 5 Time course of plasma anti-Xa activity [linear plot; mean \pm standard deviation (SD)] in subjects treated with three daily doses of $60 \mathrm{IU} / \mathrm{kg}$ of recombinant human antithrombin gamma (rhAT-gamma) $(n=10)$ or $60 \mathrm{IU} / \mathrm{kg}$ of plasmaderived antithrombin (pAT) $(n=10)$
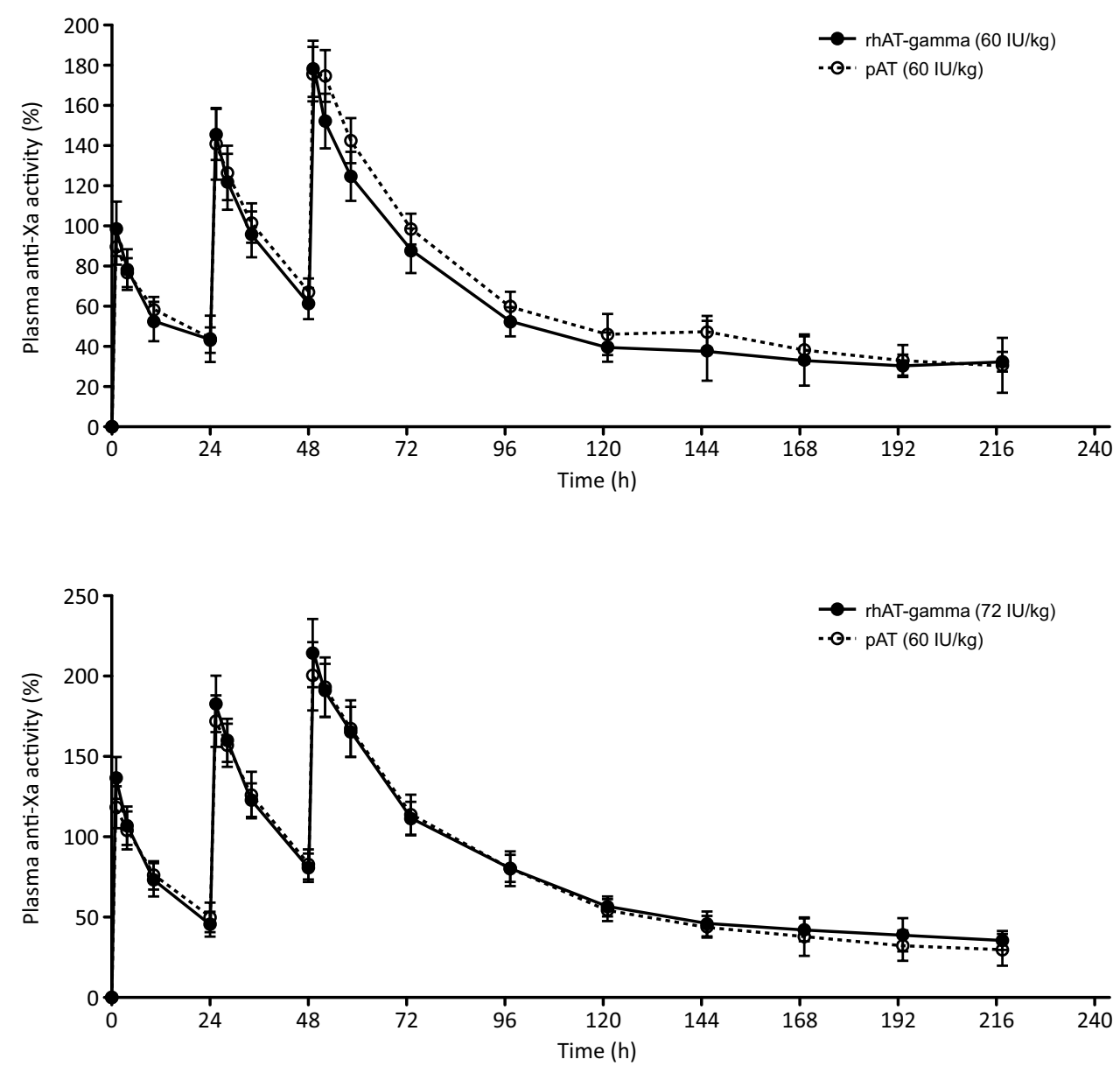

Fig. 6 Time course of plasma anti-Xa activity [linear plot; mean \pm standard deviation (SD)] in subjects treated with three daily doses of $72 \mathrm{IU} / \mathrm{kg}$ of recombinant human antithrombin gamma (rhAT-gamma) $(n=21)$ or $60 \mathrm{IU} / \mathrm{kg}$ of plasmaderived antithrombin (pAT) $(n=21)$ and all other AEs were rated as mild. Adverse drug reactions occurred in five subjects $(23.8 \%)$ in the rhAT-gamma group and no subjects in the pAT group. The ADRs were activated partial thromboplastin time prolonged in two subjects $(9.5 \%)$, and alanine aminotransferase increased, CRP increased, and rash in one subject (4.8\%) each. Prolonged activated partial thromboplastin time appeared to be associated with the blood collection technique, specimen storage method, reagents, and measuring equipment in the two affected subjects. However, because the changes occurred after study product administration, a causal relationship to the investigational drug could not be ruled out completely. All ADRs were mild in severity. 


\section{Discussion}

The biological activity of rhAT-alfa produced from the milk of transgenic goats is quite different from that of pAT owing to its unusual oligosaccharide structures. Plasma-derived antithrombin does not contain fucose, whereas rhAT-alfa contains fucose. The predominant oligosaccharide structure in rhAT-alfa is of the monosialylated and core-fucosylated biantennary complex type. Additionally, rhAT-alfa contains oligomannose- and hybrid-type oligosaccharides at Asn155. Recombinant human antithrombin alfa has four times the heparin-binding ability of pAT, but its half-life is one ninth that for pAT [15]. Given its short half-life, a continuous 24-h intravenous infusion is required [20,21].

Recombinant human antithrombin gamma is a new form of recombinant AT that has a similar sugar chain structure to native human AT. Recombinant human antithrombin gamma was developed using POTELLIGENT ${ }^{\circledR}$ technology $[16,17]$, which relies on a host Chinese hamster ovary cell line that produces fucose-free recombinant proteins. Because of its structural similarity to human AT, rhAT-gamma has pharmacokinetic and biological activities similar to those of native AT.

In the first study, comparing rhAT-gamma (60 IU/kg) and pAT (60 IU/kg), we found that the plasma AT activity of rhAT-gamma was lower than that of pAT and that plasma AT activity was quantifiable for $\sim 50 \%$ longer in the pAT group. This small reduction in rhAT-gamma activity may be attributable to slight differences in sugar chain structure, such as slightly smaller sialic acid content per AT gamma protein than per pAT protein [22]. These results demonstrated that an rhAT-gamma dose 1.2-fold higher than a pAT dose is expected to be equivalent to pAT. Therefore, 72 IU/ $\mathrm{kg}$ was considered appropriate as the rhAT-gamma dose in the second study.

The second study showed that rhAT-gamma $72 \mathrm{IU} / \mathrm{kg}$ is bioequivalent to pAT $60 \mathrm{IU} / \mathrm{kg}$. Values for $C_{\text {max,day } 3}$ and $\mathrm{AUC}_{48-t}$ were very similar in the $72 \mathrm{IU} / \mathrm{kg}$ rhAT-gamma and $60 \mathrm{IU} / \mathrm{kg}$ pAT groups. Although the ANOVA revealed significant differences $(p<0.05)$ in MRT and $t_{1 / 2}$, these differences may be attributed to two subjects in the rhAT-gamma group having much longer $t_{1 / 2}$ and MRT than other subjects in that group, and this may have skewed mean values upwards. The ANOVA also showed a significant difference between groups $(p<0.05)$ in $C_{\text {max,day } 1}$; however, the ratio between groups for $C_{\text {max,day } 1}$ (rhAT-gamma:pAT; $110 \%$ ) was very similar to that for $C_{\max , \text { day } 3}(105.7 \%)$. Thus, the statistically significant differences in these reference parameters are not considered clinically significant.

Levels of plasma AT antigen were lower in the rhATgamma group than the pAT group in the first study, but there was no obvious difference between groups in the second study. The reason for this is unknown, although it does seem that pAT contains more plasma AT antigen than rhAT-gamma.

Anti-Xa activity was also lower in the rhAT-gamma group than the pAT group in the first study, but again there was no obvious difference between groups in the second study. Anti-Xa activity is thought to be correlated with plasma AT activity.

Safety analyses indicated that once-daily rhAT-gamma for 3 days did not pose any safety concerns. At a dose of rhAT-gamma $60 \mathrm{IU} / \mathrm{kg}$, AEs were all mild, and the rate of AEs was the same as in the control group (pAT $60 \mathrm{IU} / \mathrm{kg}$ ). The incidences of AEs and ADRs were both higher in the $72 \mathrm{IU} / \mathrm{kg}$ rhAT-gamma group. Eight of the 13 AEs in this group occurred after hospital discharge, and several were likely caused by unrelated events such as dental procedures and alcohol intake. All ADRs were mild in severity.

The findings of these studies should be considered in light of several limitations. The main limitations were the small sample size and lack of generalizability to other populations because the sample comprised healthy adult Japanese men aged 20-45 years. Another limitation is that the investigational drug dose was repeated for only 3 days to measure AUC. However, this differs from treatment duration for patients in actual clinical practice.

\section{Conclusions}

Overall, the present data support rhAT-gamma as a safe alternative to pAT products. Based on these data, the rhATgamma intravenous formulation of $600 \mathrm{IU}$ (ACOALAN ${ }^{\circledR}$ injection 600) was approved in 2015, and the rhAT-gamma intravenous formulation of $1800 \mathrm{IU}$ (ACOALAN ${ }^{\circledR}$ injection 1800) was approved in 2017, by the Ministry of Health, Labour and Welfare in Japan. These formulations are currently being used for the treatment of thrombophilia caused by congenital AT deficiency and disseminated intravascular coagulation.

Acknowledgements Recombinant human AT gamma is being developed by Kyowa Kirin Co., Ltd. Susan Cottrell, Ph.D., and Keyra Martinez Dunn, MD, of Edanz Medical Writing provided medical writing support.

Author Contributions All authors participated in the conception and design of the study. All authors were involved in analysis and interpretation of the data. HF drafted the manuscript. HF and HK provided intellectual content of critical importance. All authors revised and approved the final version of the manuscript.

Data Sharing Data sets from this study will be made available upon appropriate request. 


\section{Compliance with Ethical Standards}

Funding This study was funded by Kyowa Kirin Co., Ltd.

Conflict of interest Hidetoshi Furuie has received consulting/lecture fees and research funding from Kyowa Kirin Co., Ltd. Hironori Kanda is an employee of Kyowa Kirin Co., Ltd.

Ethics approval All procedures performed in studies involving human participants were in accordance with the ethical standards of the Institutional Review Board at Osaka Pharmacology Clinical Research Hospital, Osaka, Japan (approval no. 787PC and no. 814PC) and with the 1964 Helsinki Declaration and its later amendments or comparable ethical standards.

Consent to participate Informed consent was obtained from all individual participants included in the study.

Open Access This article is distributed under the terms of the Creative Commons Attribution-NonCommercial 4.0 International License (http://creativecommons.org/licenses/by-nc/4.0/), which permits any noncommercial use, distribution, and reproduction in any medium, provided you give appropriate credit to the original author(s) and the source, provide a link to the Creative Commons license, and indicate if changes were made.

\section{References}

1. Zhu Y, Cong QW, Liu Y, et al. Antithrombin, an important inhibitor in blood clots. Curr Top Med Chem. 2016;16:666-74.

2. Damus PS, Hicks M, Rosenberg RD. Anticoagulant action of heparin. Nature. 1973;246:355-7.

3. Olson ST, Bjork I. Regulation of thrombin activity by antithrombin and heparin. Semin Thromb Hemost. 1994;20:373-409.

4. Rosenberg RD. Biochemistry of heparin antithrombin interactions, and the physiologic role of this natural anticoagulant mechanism. Am J Med. 1989;87:2s-9s.

5. Jin L, Abrahams JP, Skinner R, Petitou M, Pike RN, Carrell RW. The anticoagulant activation of antithrombin by heparin. Proc Natl Acad Sci U S A. 1997;94:14683-8.

6. Carlson TH, Simon TL, Atencio AC. In vivo behavior of human radioiodinated antithrombin III: distribution among three physiologic pools. Blood. 1985;66:13-9.

7. Rosenberg RD, Damus PS. The purification and mechanism of action of human antithrombin-heparin cofactor. J Biol Chem. 1973;248:6490-505.

8. Patnaik MM, Moll S. Inherited antithrombin deficiency: a review. Haemophilia. 2008;14:1229-39.

9. Maclean PS, Tait RC. Hereditary and acquired antithrombin deficiency: epidemiology, pathogenesis and treatment options. Drugs. 2007;67:1429-40.
10. Kumar R, Chan AK, Dawson JE, Forman-Kay JD, Kahr WH, Williams S. Clinical presentation and molecular basis of congenital antithrombin deficiency in children: a cohort study. Br J Haematol. 2014;166:130-9.

11. Wada H, Asakura H, Okamoto K, et al. Expert consensus for the treatment of disseminated intravascular coagulation in Japan. Thromb Res. 2010;125:6-11.

12. MacLennan S, Barbara JA. Risks and side effects of therapy with plasma and plasma fractions. Best Pract Res Clin Haematol. 2006;19:169-89.

13. Edmunds T, Van Patten SM, Pollock J, et al. Transgenically produced human antithrombin: structural and functional comparison to human plasma-derived antithrombin. Blood. 1998;91:4561-71.

14. Paidas MJ, Forsyth C, Quere I, Rodger M, Frieling JT, Tait RC. Perioperative and peripartum prevention of venous thromboembolism in patients with hereditary antithrombin deficiency using recombinant antithrombin therapy. Blood Coagul Fibrinolysis. 2014:25:444-50.

15. Yamada T, Kanda Y, Takayama M, et al. Comparison of biological activities of human antithrombins with high-mannose or complextype nonfucosylated N-linked oligosaccharides. Glycobiology. 2016;26:482-92.

16. Matsushita T. Engineered therapeutic antibodies with enhanced effector functions: clinical application of the POTELLIGENT ${ }^{\circledR}$ Technology. Korean J Hematol. 2011;46:148-50.

17. Yamane-Ohnuki N, Kinoshita S, Inoue-Urakubo M, et al. Establishment of FUT8 knockout Chinese hamster ovary cells: an ideal host cell line for producing completely defucosylated antibodies with enhanced antibody-dependent cellular cytotoxicity. Biotechnol Bioeng. 2004;87:614-22.

18. Marzo A, Ceppi-Monti N, Giusti A, Abbiati G, Parenti M. Pharmacokinetic behaviour of antithrombin III following intravenous infusion in healthy volunteers. Arzneimittelforschung. 2002;52:187-93.

19. Partial Revision of the Guidelines for Bioequivalence Studies of Generic Products (PFSB/ELD Notification No. 0229-10 dated February 29, 2012 issued by the Director of Evaluation of Licensing Division, Pharmaceutical and Food Safety Bureau, Ministry of Health, Labour and Welfare). Available from: http://www.nihs. go.jp/drug/be-guide(e)/Generic/GL-E_120229_BE.pdf. Accessed 26 June 2019.

20. Dickneite G. A comparison of the pharmacokinetics of antithrombin derived from human plasma and from transgenic goats and the prevention of sepsis in an animal model. Biopharm Drug Dispos. 2008;29:356-65.

21. Dennis JC, Terri LL, Danial EB. Formulary drug reviews: antithrombin (recombinant). Hosp Pharm. 2009;44:758-93.

22. Endo S, Shimazaki R, Antithrombin Gamma Study Group. An open-label, randomized, phase 3 study of the efficacy and safety of antithrombin gamma in patients with sepsis-induced disseminated intravascular coagulation syndrome. J Intensive Care. 2018;6:75. 